\title{
Ion Exchange Technology Development in Support of the Urine Processor Assembly Precipitation Prevention Project for the International Space Station
}

\author{
Julie L. Mitchell ${ }^{1}$, James L. Broyan ${ }^{2}$, Karen D. Pickering ${ }^{3}$, Niklas Adam ${ }^{4}$ \\ NASA Johnson Space Center, Houston, TX, 77058 \\ Michael Casteel ${ }^{5}$, Michael Callahan ${ }^{6}$, Chris Carrier $^{7}$ \\ Jacobs Technology, Houston, Texas, 77058
}

In support of the Urine Processor Assembly Precipitation Prevention Project (UPA PPP), multiple technologies were explored to prevent $\mathrm{CaSO}_{4} \cdot 2 \mathrm{H}_{2} \mathrm{O}$ (gypsum) precipitation during the onorbit distillation process. Gypsum precipitation currently limits the water recovery rate onboard the International Space Station (ISS) to $70 \%$ versus the planned $85 \%$ target water recovery rate. Due to its advanced performance in removing calcium cations in pretreated augmented urine (PTAU), ion exchange was selected as one of the technologies for further development by the PPP team. A total of 12 ion exchange resins were evaluated in various equilibrium and dynamic column tests with solutions of dissolved gypsum, urine ersatz, PTAU, and PTAU brine at $85 \%$ water recovery. While initial evaluations indicated that the Purolite SST60 resin had the highest calcium capacity in PTAU (0.30 meq/mL average), later tests showed that the Dowex G26 and Amberlite FPC12H resins had the highest capacity $(0.5 \mathrm{meq} / \mathrm{mL}$ average). Further dynamic column testing proved that G26 performance is $+/-10 \%$ of that value at flow rates of 0.45 and $0.79 \mathrm{Lph}$ under continuous flow, and 10.45 Lph under pulsed flow. Testing at the Marshall Spaceflight Center (MSFC) integrates the ion exchange technology with a UPA ground article under flight-like pulsed flow conditions with PTAU. To date, no gypsum precipitation has taken place in any of the initial evaluations.

\footnotetext{
${ }^{1}$ Water Hardware \& Technology Engineer, Crew \& Thermal Systems Division, M/S: EC3, not AIAA affiliated.

${ }^{2}$ Urine Precipitation Prevention Project Manager, Crew \& Thermal Systems Division, M/S: EC3, not AIAA affiliated.

${ }^{3}$ Water Hardware \& Technology Group Lead, Crew \& Thermal Systems Division, M/S: EC3, not AIAA affiliated.

${ }^{4}$ Water Hardware \& Technology Chemist, Crew \& Thermal Systems Division, M/S: EC3, not AIAA affiliated.

${ }^{5}$ Water Hardware \& Technology Environmental Engineer, Crew \& Thermal Systems Division, M/S: EC3, not AIAA affiliated.

${ }^{6}$ Water Hardware \& Technology Environmental Engineer, Crew \& Thermal Systems Division, M/S: EC3, not AIAA affiliated.

${ }^{7}$ Water Hardware \& Technology Chemist, Crew \& Thermal Systems Division, M/S: EC3, not AIAA affiliated.
} 